\title{
EL PROYECTO SINARQUISTA DE LA COLONIZACIÓN DE BAJA CALIFORNIA (1941-1943)
}

\author{
POR \\ PABLO SERRANO ÁLVAREZ \\ Instituto de Investigaciones Históricas-UNAM \\ Centro de Investigaciones Sociales-Universidad de Colima
}

\section{INTRODUCCIÓN}

En agosto de 1940, Salvador Abascal fue nombrado jefe nacional de la Unión Nacional Sinarquista (UNS), que por ese entonces ya se había convertido en una de las principales fuerzas de oposición al régimen posrevolucionario. La movilización de protesta contra la política cardenista, la tendencia de la educación socialista, las aplicaciones y funcionamiento de la reforma agraria, el manejo y doctrina de las organizaciones oficiales (Confederación de Trabajadores de México (Confederación Nacional Campesina, Partido de la Revolución Mexicana) y las manifestaciones de los principales líderes de cariz comunista y socialista, evidenciaron la fortaleza de un movimiento que se auto definía como

SIGLAS UTILIZADAS:

ACNUS-BINAH: Archivo del Comité Nacional de la Unión Sinarquista Biblioteca del Instituto Nacional de Antropología. México DF.

ACRUNS-León: Archivo del Comité Regional de la Unión Nacional Sinarquista. León. Guanajuato.

AGN-UP-FMAC: Archivo General de la Nación, México. Unidad Presidentes. Fondo M. Avila Camacho.

UNS: Unión Nacional Sinarquista.

Agradezco a Jorge Amao, Ignacio del Río, Gisela Von Wobeser y Martha Loyo, los apoyos y estímulos para la realización de este trabajo. Deseo reconocer aquí las opiniones y comentarios recibidos por Jean Meyer y Servando Ortoll. Mi agradecimiento a Gabriel Anguiano, testimonio presente de la utopía sinarquista. Reconozco las opiniones y críticas de los miembros del Seminario de Historia Contemporánea de México y del Seminario de Historia Regional, ambos desarrollados en el Instituto de Investigaciones Históricas de la UNAM. La corrección de estilo fue realizada por Alejandro Aguilar. 
"católico", "espiritual», "nacionalista" "popular" y "contrarrevolucionarion.

El líder Abascal incrementó la fortaleza y presencia del movimiento sinarquista en la sociedad mexicana, a través de un marco ideológico, psicológico y estratégico, que no sólo acrecentó la militancia sino incrementó el grado de protesta social contra el régimen. La obsesión por la disciplina y el orden, el catolicismo tradicional y la defensa de la Iglesia, el nacionalismo y el hispanismo, la salvación social e individual y el ataque furibundo contra todo lo que significaba revolución, pronto atrajeron a las masas y dieron una presencia cotidiana a la movilización sinarquista.

Abascal supo aprovechar la política de la "unidad nacional» de Ávila Camacho para incrementar la presencia del sinarquismo como fuerza sociopolítica, aunque lo negara. El nuevo presidente de México, considerado en la época como de la centro-derecha oficial, y después de haber pactado con los sinarquistas en el proceso de campaña, se manifestó moderado y conciliador a pesar de las críticas que Abascal había impuesto al movimiento.

Hacia fines de 1940, el sinarquismo contaba en sus filas con más de cien mil militantes activos en todo el país. El líder Abascal se propuso que ese apoyo masivo, conformado básicamente por campesinos, obreros y sectores medios, se canalizara públicamente en todas sus dimensiones, desde la protesta furibunda hasta la presencia cotidiana en la opinión pública nacional. Las "grandes marchas» sobre las ciudades principales del Bajío, los ataques periodísticos contra la política estatal o los adversarios comunistas, cardenistas o socialistas, las declaraciones inflamadas de ideología católica y nacionalista, y la expresión obsesiva del proyecto de orden social cristiano-sinárquico fueron la tónica del movimiento dominado por la personalidad de Abascal. Las respuestas adversarias no hicieron más que incrementar el apoyo social y la presencia sinarquistas, cuestión que Abascal aprovechó para llevar a cabo algunos proyectos que incrementarían la fortaleza del movimiento y probarían su capacidad de oposición contra el gobierno avilacamachista. Las relaciones de la UNS con el gobierno fueron buenas, a pesar de los constantes ataques y críticas que los sinarquistas hacían al régimen.

Fue entonces cuando el líder Abascal contempló la posibilidad de la colonización surcaliforniana, empresa descabellada que debilitó al movimiento y puso al descubierto, en todas sus dimensiones, la ideología conservadora, idealista y autoritaria que aquel 
líder había impuesto al sinarquismo. La simple idea de la colonización fue una utopía, una idealización personal de Abascal, que deseaba rescatar, en pleno siglo XX, el papel de los misioneros jesuitas o franciscanos en los siglos XVI al XVIII, para demostrar que con "sacrificio", "fe" y "espíritu" se podía llevar a cabo el ideal católico-sinarquista en todos sus puntos. La conciliación con el presidente y la fortaleza y presencia del movimiento sinárquico aceleraron el proyecto de la colonización, pues era el momento adecuado para lograr los apoyos, sobre todo de orden económico, que Abascal necesitaba para materializar su ideal. Los sinarquistas lo siguieron con vehemencia, pues la uprovidencia" había convertido a Abascal en el "salvador divino" del pueblo mexicano, y la colonización era una prueba más. La historia, sin embargo, fue dramática, triste y cruel, tanto para el mismo Abascal como para el movimiento sinarquista en su conjunto.

\section{El PROYECTO}

En agosto de 1941, un año después de haber tomado posesión de la jefatura nacional de la UNS, Salvador Abascal realizó un viaje por Baja California Sur. Fue entonces cuando se le ocurrió la idea de la colonización. Esa idea representó una obsesión:

Sin descuidar ninguno de los aspectos de la lucha sinarquista, vamos a poner todo nuestro empeño en colonizar el Distrito Sur de la Baja California. Lo haremos, Dios mediante, con mucha lentitud, pero sin retroceder ante ningún obstáculo. Vamos a llevar voluntarios sinarquistas. El primer paso es instruir a todos los nuestros acerca de lo que es la Baja California. Para eso escribo estas notas que tomé durante mi reciente viaje a la península: quiero que todos los sinarquistas vean lo que yo vi y ansíen lo que yo ansío (1).

Según el mismo Abascal, la idea no era tan descabellada y sí necesaria. La Baja California contaba apenas con 51.000 habitantes y era una región aislada (pero también estratégica), que por tanto peligraba por la ambición «judía» de los estadounidenses. Si el sinarquismo luchaba por la unión de los mexicanos, entonces

(1) Salvador Abascal. Mis recuerdos sinarquismo y Maria Auxiliadora (19.51944) con importantes documentos de los Archivos Nacionales de Washington, prólogo de Salvador Borrego, México, Tradición, 1980, págs. 291-292. Tal cual me lo reiteró un viejo sinarquista, Dr. Rubén Mangas Alfaro, en entrevista celebrada en el Distrito Federal el 77 de mar\%o de 1988. 
la colonización de ese territorio enlazaria «espiritual y materialmente" a los bajacalifornianos con sus connacionales. Al mismo tiempo se protegería a Sonora y Sinaloa de la «inquina yanqui», que buscaba tener en su poder al territorio y arrastrar las "almas" hacia el protestantismo judio (2).

El viaje de reconocimiento impactó a Abascal, pues consideró que el clima era benigno, los campos eran extensos y deshabitados y los nativos veían con buenos ojos que el sinarquismo se convirtiera en el colonizador de ese territorio (3). La zona de Santo Domingo fue la que más agradó a Abascal para poner allí el primer asentamiento expedicionario, pues le impresionaron el buen clima que existía y la forma en que catorce familias vivían de los cultivos de subsistencia (4). La carencia de una vida católica preocupó a Abascal, pues sólo existían tres sacerdotes en todo el territorio sur y, por ende, no había quién guiara a los «espíritus», lo que hacía necesaria la acción del sinarquismo (5).

Desde que Abascal salió del territorio bajacaliforniano, en agosto de 1941, se empezó a cuajar el proyecto de la colonización como una experiencia que rescataría la lucha misionera de los jesuitas que, junto con la estrategia franciscana, insertaría al sinarquismo dentro de los "grandes sacrificios" de los "cruzados católicos». De la misma forma, el sinarquismo ayudaría a poblar una región deshabitada, inhóspita y aislada, que podría convertirse en un tesoro alcanzable para los estadounidenses. La unión nacional (territorial y espiritual) era así cristalizada por el líder del sinarquismo, cuestión que no se oponía para nada a los postulados avilacamachistas y, tampoco, a la doctrina católica que manejaba los dictados de la Iglesia y de la organización secreta que dirigía a la UNS (6).

(2) Ibid., págs. 292, 293 y ss. Cfr. con James Wilkie y Edna Monzón de Wilkie, entrevista con el Lic. Salvador Abascal, realizada en la ciudad de México el 17 de agosto de 1964, Programa de Historia Oral, Universidad de California-Berkeley y El sinarquista, (México, D. F.): mes de septiembre de 1941. Además, "Ideas sobre la colonización de Baja California Sur", mecanoescrito sin autor, fechado el 16 de octubre de 1941, ACRUNS-León, Gto. Este mismo documento se encuentra en ACNUNS-BINAH, rollo 12.11.23.

(3) ABASCAL [1], págs. 294-300.

(4) Ídem, págs. 300, 301 y El sinarquista, números de septiembre de 1941.

(5) ABASCAL [1], pág. 307.

(6) Ver, al respecto, las apreciaciones de Jean Meyer. El sinarquismo, iun fascismo mexicano? 1937-1947, trad. de Aurclio Garzón, México, Joaquín Mortiz., 1979, (cuadernos Joaquín Mortiz). Sobre la labor misionera, y el pensamiento de Abascal en este sentido ver ibid., págs. 337 y ss. Acerca de la ideología de Abascal, en su conjunto, véase Pablo Serrano Alvarkz. La "batalla del espiritu": el movimiento sinarquista en el Bajio (1934-1952), en prensa por el Consejo Nacional para la Cultura y las Artes. 
Los objetivos fueron muy claros para Abascal:

El principal objeto que yo perseguía era fundar un pueblo o varios pueblos netamente cristianos que vivieran conforme al ideal católico; que en lo social y político llegaran a servir de modelo. A la vez pretendí empezar una obra de colonización que a mi juicio era urgentísima para salvar no sólo a la península californiana, sino a Sonora, Sinaloa y Nayarit y, por lo tanto a la Patria mexicana (7).

En los primeros días de septiembre (1941), el líder del sinarquismo propuso la colonización bajacaliforniana a los dirigentes de la organización secreta, llamada La Base, y al propio presidente Ávila Camacho. Para la realización de esta obra debía contar con apoyos financieros importantes, que sólo se podían conseguir con las colectas que realizaba la UNS con sus militantes, los supuestos apoyos económicos de los ricos que conformaban el mando supremo de La Base (donde también participaba la alta jerarquía católica), y el apoyo del gobierno. Abascal solicitó ayuda al presidente Ávila Camacho, of reciendo el proyecto como una colaboración del movimiento con la obra gubernamental de la «unidad nacional». El presidente contestó, por intermedio de su secretario particular, el 12 de septiembre de 1941:

El C. Presidente de la República quedó enterado del mensaje que con fecha 2 del actual le dirigió por el cual le ofrece la organización que usted preside un plan de colaboración inmediata, tendiente a colonizar en breve plazo, con familias sinarquistas, los terrenos actualmente desérticos de la Baja California, para dedicarse al cultivo de la tierra, construcción de carreteras y creación de nuevas industrias.

A este respecto, el propio Primer Magistrado me ha encomendado manifestar a usted que acepta la colaboración que of rece y espera se sirva indicarle el plan que proyecta, así como las facilidades que desea se le otorguen por parte del gobierno de la República (8).

El proyecto presentado al presidente y a Antonio Santacruz, jefe supremo de La Base, consistió, básicamente, en siete puntos: 1) Libertad para movilizar a familias sinarquistas que la misma

(7) Abascal [1], pág. 338.

(8) Este documento, junto con la petición del día 2 de septiembre, de Abascal, se encuentran en AGN-UP-FMAC, exp. 544.61/39. El telegrama se encuentra reproducido también èn ABASCal [1], pág. 339. 
UNS seleccionara; 2) Que la primera expedición se compondría de 100 familias a lo sumo, que partirían a Baja California en diciembre de 1941 ; 3) Que en la segunda expedición irian 1.000 familias, que llegarian en el mes de febrero de 1942; 4) Que los colonizadores se encargarían de realizar los trabajos para la construcción de una carretera de 600 kilómetros, conjuntamente con el gobierno federal, entre La Paz y Santa Rosalía; 5) Que los expedicionarios serían transportados con cargo al gobierno federal, desde sus lugares de origen hasta $\mathrm{La} \mathrm{Paz;} \mathrm{6)} \mathrm{Que} \mathrm{a} \mathrm{los}$ colonizadores se les dejara en plena posesión y propiedad de las tierras nacionales que escogieran, y que, además, no se les cobrara ninguna contribución por más de cinco años; y 7) Que hubiera garantías suficientes para que la colonia tuviera «libertad absoluta" en lo religioso y educativo (9).

Abascal tuvo audiencia con el presidente en el Palacio Nacional el día 30 de septiembre. Ávila Camacho prometió toda la ayuda necesaria para que se realizara el proyecto, por lo que esto puso muy contento al líder sinarquista, que enseguida dio a conocer a la militancia la urgencia y necesidad de la obra colonizadora (10).

Además, Santacruz prometió gestionar con los católicos estadounidenses un apoyo financiero suficiente para la obra de colonización. Abascal anunció, entonces, que la primera expedición saldría el 18 de diciembre de aquel año, y se empezaron los trabajos de selección de la gente adecuada para la "obra salvadora y misionera" (11).

La obsesión de Abascal resultó exagerada. En el mismo cuestionario para la selección de la gente se exigían los siguientes datos:

... a) Nombre y apellidos materno y paterno; b) edad; c) domicilio actual; d) oficio; e) grado de instrucción; f) salud (enfermedades que haya padecido, vigor físico, etc.); g) estado civil. Anotar si

(9) Ver "Proyecto de colonización de la Baja California" de Salvador Abascal en AGN-UP-FMAC, Exp. 544.61/39. El mismo proyecto se encuentra en ACRUNSLeón, Gto. y una parte, modificada en redacción, está publicada en ABAscal. [1], pág. 343. Para reafirmar ver Mfyer 60 y Cfr. con Anne-Marie de la Vega, Histoire du monvement sinargiste, 1934-1944, contribution a l'histoire du Mexique contemporain, Thése de III cycle, París I, 1975, vol. 1. 1941.

(10) El sinarquista (México D.F.): números correspondientes a octubre de

(11) Instrucciones del jefe a los lideres estatales de Michoacán, Guanajuato y Querétaro, octubre de 1941, en ACRUNS-León, Gto. Ampliar lo anterior con Servando Ortoll, "La colonización bajacaliforniana del sinarquismo, en el contexto de la Segunda Guerra Mundial", mecanoescrito incédito. 
está unido en matrimonio religioso); h) familia (nombres, edades, estado, oficio, domicilio y salud de sus deudos); f) cuáles de esos deudos lo acompañarán. (La colonia sinarquista se integrará por grupos familiares); j) qué bienes tiene, cuales deja; k) que instrumentos de trabajo y qué muebles llevará (12).

La planificación de la colonización se hizo sin saber las necesidades, los obstáculos y la cantidad de recursos que se requerían. Perduró la intuición del líder Abascal que, por su personalidad obsesiva, dejó todo a la "providencia», al "espíritu santo" y a la "fuerza divina». Jamás contó con un plan que visualizara el conjunto de necesidades y obstáculos, aún las características de la gente que iba a colonizar.

El 7 de octubre, Abascal se entrevistó con el secretario de gobernación, Miguel Alemán, y con el gobernador del territorio, Francisco J. Mújica, para ultimar los detalles del apoyo gubernamental que, por cierto, nunca recibiría (13).

El entusiasmo del líder sinarquista fue mayúsculo, acompañándole los militantes que apoyaron la iniciativa, deseando convertirse en los "misioneros de la salvación de México". Pronto se escogió el lugar para la primera fundación, de acuerdo con los consejos de varios técnicos que apoyaron a Abascal. El valle de Santo Domingo, a 320 kilómetros de La Paz, era el lugar designado para la "gran obra colonizadora" del sinarquismo. La utopía del proyecto era impresionante en la mentalidad de Abascal:

Los colonos de la primera expedición se dedicarán a la agricultura, para lo cual ya tenemos localizadas buenas tierras en las cuales caben perfectamente hasta 400 pequeños propietarios, dedicados con sus familias a cultivos intensivos. Esas tierras son excelentes para la parra, el olivo, la higuera, el dátil. Se dan también, admirablemente, en ellas el chícharo, el haba, la lenteja, el chile, el tomate, la alfalfa, la sandía. Se levantan dos cosechas de maíz y de frijol.

(...)

De la segunda expedición unos se dedicarán también a la agricultura, otros a la industria: calzado, ropa, pesca, etc., y otros muchos a la construcción de la carretera que el gobierno federal quiere emprender para unir La Paz con Santa Rosalía con el Distrito Norte. (...)

Dentro de un año saldrán más expediciones y seguirán sa-

(12) Abascal [1], pág. 342. Las instrucciones también se encuentran en ACRUNS-León, Gto.

(13) Abascal [1], pág. 344. 
liendo después hasta que en cinco años tripliquemos la población del Distrito Sur, (...) (14).

Abascal había pensado que Manuel Zermeño, jefe nacional del sinarquismo en el período posterior, podía hacerse cargo de la obra colonizadora, pero La Base no lo permitió, pues sus miembros deseaban separar a Abascal de la dirigencia nacional, por su uradicalismo opositor al gobierno y su yancofobia». Abascal aceptó aunque inconsciente de la intriga que Santacruz había tramado contra él $y$, sobre todo, de las verdaderas razones para encomendarle el proyecto colonizador del sinarquismo (15).

La ayuda del presidente Ávila Camacho, para que el proyecto se realizara, ocasionó la protesta de los adversarios de los sinarquistas, principalmente de los diputados cetemistas comandados por Félix Díaz Escobar, que vieron como peligrosa la obra colonizadora. Según sus apreciaciones, el sinarquismo era financiado y apoyado por el fascismo europeo - italiano, alemán y españolpara tener un punto estratégico en el país y así combatir a los estadounidenses. Protestaron ante el presidente por ese apoyo y pusieron en la opinión pública la versión de que el movimiento sinarquista, efectivamente, era un fascismo mexicano y que la obra de la colonización pretendía luchar contra los Estados Unidos, para arrebatarles el territorio que habían obtenido como producto de la guerra de 1847. Las acusaciones eran absurdas, y Abascal instruyó a los sinarquistas para que hicieran caso omiso de las acusaciones que, realmente, eran descabelladas (16).

Durante los meses de octubre, noviembre y diciembre, sin embargo, la UNS se dedicó a preparar la expedición de los "cruzados", "misioneros" y "providenciales" sinarquistas, que de esta forma colaboraban en "bien de la Patria» y la "unidad nacional». Abascal se sintió como el "enviado de la providencia divina" para realizar esta obra "católica y misionera", aunque después aparecería la frustración y el desencanto.

El jefe supremo de La Base, Santacruz, envió a la UNS un técnico holandés, experto en agricultura y colonización de tierras,

(14) ABASCAL [1], págs. 351, 352.

(15) Entrevista de Servando Ortoll y Pablo Serrano Álvarez, con el Ing. Gildardo González Sánchez, realizada en la ciudad de Colima el 11 de junio de 1989. Cfr. con la entrevista de James Edna Wilkie con ABASCAL [2]. Ver las apreciaciones de MEYER [6], op. cit.

(16) Ver AGN-UP-FMAC, exps. 542.1/2371 y 542.1/38, leg. 3. Las respuestas de la UNS se encuentran en extensos boletines de prensa, consultados en ACRUNS-León. 
que fue el que ayudó a Abascal en el proceso de planificación. Wiegman partió a Baja California, acompañado de Pedro Vargas Covarrubias, Felipe Vázquez y Prisciliano Murillo, para analizar las posibles necesidades de los futuros colonos y tantear el tipo de cultivos, la manera de irrigar y hacer una lista de materiales. Bajo los análisis de Wiegman, Abascal se lanzó a la colonización (17).

Hacia fines del mes de noviembre, los dirigentes de La Base pidieron a Abascal que él fuera el jefe de la colonización, pues en realidad era una obra que había sido proyectada por él mismo. Por lo tanto, tenía que entregar la jefatura nacional de la UNS. El 12 de diciembre entregó el mando a Manuel Torres Bueno, para dedicarse de lleno a la obra colonizadora. Según Abascal, el cambio de mando había sido una «jugarreta» de Santacruz, la embajada estadounidense y el gobierno avilacamachista, que deseaban apartarlo por sus críticas y radicalismos oposicionistas, pero esto lo había entendido ya cuando la obra de la colonización había fracasado. El nuevo líder nacional del sinarquismo pertenecía a los cuadros medios del movimiento, y era de los más moderados y manejables para los fines de la organización secreta. Abascal lo había escogido con la anuencia de Santacruz, aunque después se arrepintió por el poco apoyo que brindó a la experiencia bajacaliforniana (18).

Abascal, sin embargo, vio el cambio como "providencial». Implicaba un "sacrificio" y una "cruzada" que lo llenaba de satisfacción, porque su utopía idealista y conservadora por fin se realizaba (19).

Las complicaciones empezaron ocho días antes de que saliera la expedición sinarquista, sobre todo porque los apoyos del gobierno nunca llegaron para el transporte y tampoco los recursos de los católicos estadounidenses, prometidos por Santacruz. La primera expedición se realizó con los recursos aportados por los mismos militantes sinarquistas que, mediante diversas colectas y donaciones, permitieron la realización del proyecto. La primera expedición fue «bautizada» por Abascal como "María Auxiliadora” (20).

(17) ABASCAL [1], pág. 377. Cfr. con extenso material de la planificación de la colonia en ACRUNS-León.

(18) Abascal., pág. 435. Ver correspondencia de Abascal, entre el 15 de noviembre y el 12 de diciembre de 1941 en ACRUNS-León. Cfr. con MEYER [6] y DE LA VEGA [9], vol. 2.

(19) Abascal [1], pág. 435. Cfr. Entrevista de James y Edna Wilkie con Abascal [2].

(20) Abascal [1], pág. 442. 
La UNS, desde el momento de la colonización, inició un proceso de declive que la condujo a su casi desaparición como una organización que movilizaba a las masas contra el Estado posrevolucionario, desde el lado de la derecha. Los conflictos de la colonización enfrentaron a los líderes, a los militantes, a los colonos y a la organización con La Base, la Iglesia y el gobierno. Durante tres años, el proyecto y la obra hicieron saltar la putrefacción del movimiento sinarquista y sus debilidades. Abascal fue el principal actor de esta realidad.

\section{LA REALIZACIÓN}

Después de diversos problemas en el proceso de selección de los colonos, la carencia de recursos para transportes y la compra de las necesidades más apremiantes, la expedición sinarquista a la Baja California Sur partió el 18 de diciembre de 1941, desde diversos puntos del centro de México. Los expedicionarios salieron del Distrito Federal, León, Querétaro, Acámbaro, Ario de Rosales, Pátzcuaro y Morelia. Todos los colonos escogidos por Abascal eran de esos lugares, pues según sus apreciaciones, esa gente era la que más soportaba los sacrificios y la que más sabía de agricultura y, sobre todo, era la más "moral» y "católica» del país. La expedición se compuso de 85 familias, con un gran total de 400 personas que se reunieron en la ciudad de Guadalajara, para partir de ahí a Mazatlán y tomar un transbordador a La Paz (21).

Las características de los colonizadores, emocionaron al «cruzado" Abascal:

Y los expedicionarios sabian también, con el resto de los sinarquistas, que iban a la península para no volver, para quedarse a vivir allá hasta la muerte, puesto que sólo así es posible colonizar un país desierto; y que iban como soldados, que voluntariamente se habían of recido y alistado pero como verdaderos soldados de un movimiento patriótico en una empresa eminentemente patriótica, de la cual no podrían desertar so pena de ser considerados automáticamente fuera del Movimiento (22).

(21) "Estadísticas de la colonización de Baja California", diciembre de 1941, en ACRUNS-León. Este documento se encuentra reproducido también, en partes, en ACNUNS-BINAH, rollo 12.33.44.

(22) ABASCAL [1], pág. 445. El autoritarismo permeó el manejo que hizo Abascal de la colonización. La amenaza de expulsión y rigidez fueron la tónica. 
El traslado de la gente tuvo que hacerse con las propias donaciones de los sinarquistas, pues los apoyos gubernamentales, como se dijo más arriba, nunca llegaron.

Tres destacados miembros de la Brigada Nacional de Propaganda de la UNS, como Ramón de Anda, Jesús Sam López y Valentín Lozada, acompañaron a Abascal en el viaje. En Guadalajara celebraron una junta en la que se instruyó a los expedicionarios sobre el viaje a Mazatlán, y se celebró una misa donde se cantaron los himnos del movimiento. En Mazatlán, los expedicionarios se embarcaron rumbo a La Paz, en el barco «Salvatierra». Apenas cupieron las 85 familias (compuestas, aproximadamente, de 400 personas), pero Abascal ansió, "por la providencia", la llegada de la misión completa. El gobernador del territorio Francisco J. Mújica, por intermedio de Manuel Zermeño que se encontraba en La Paz, autorizó desde allá que el barco zarpara así. desde Mazatlán (23).

Los colonos sinarquistas llegaron a La Paz el 29 de diciembre, después de dos días de travesía. Se acomodó a la gente en una bodega, mientras que Abascal, los propagandistas y Zermeño arreglaron el traslado a Santo Domingo, donde se asentaría "María Auxiliadora". Se obtuvo todo el apoyo del gobernador Mújica y el secretario de gobierno, de apellido Billarent, pues la expedición no llevaba recursos para el traslado. Finalmente el 1 de enero de 1942, los expedicionarios partieron al lugar escogido por Abascal para el asentamiento de la colonia. El entusiasmo del líder desbordó:

María Auxiliadora sería una comunidad católica, inatacable, que podría vivir, en lo privado y en lo público, conforme a nuestro ideal católico. Hasta entonces las relaciones de los sinarquistas entre sí y de éstos con sus jefes no habían abarcado más que el aspecto cívico de los desfiles y asambleas: la vida social no nos había pertenecido. Ahora sí la teníamos en nuestras manos. Había sido menester irnos al desierto californiano para conquistar el derecho de agruparnos estrechamente y de vivir socialmente, en comunidad perfecta, todas y cada una de nuestras ideas (24).

El asentamiento sinarquista se formó de chozas de mezquite y hierba, y se empezaron los trabajos para cultivar en el terreno

(23) ABASCAL [1], pág. 448. Ésto lo confronté en una entrevista con Ramón Torres Robles, celebrada en León, Gto. el día 16 de abril de 1988. Igual se afirma en la entrevista de James y Edna Wilkie con Salvador Abascal [2].

(24) Abascal [1], pág. 455. 
escogido para ese efecto. Casi de inmediato hubo problemas de deserción, pues mucha gente no aguantó el ritmo de trabajo y la rigidez a la que fue sometida por Abascal.

En enero de 1942 el jefe de la colonia ya tenía un proyecto de "constitución" interna, donde se plasmaban los por qués del asentamiento, así como las reglas del juego. 27 eran los puntos: 1) Se declaraba que en nombre de la "santísima trinidad" la colonia se llamaba "María Auxiliadora»; 2) Que basándose en los preceptos católicos se buscaba formar una península de misioneros, que sirvieran a "América y el Mundo", dedicándose al "amparo y patrocinio" de la "Virgen de Guadalupe" y otros símbolos religiosos; 3) El jefe de la colonia tenía que sujetarse a las leyes de la Iglesia Católica, tanto en sus acciones como disposiciones; 4) El jefe tenía por obligación escuchar las proposiciones de los distintos jefes de familia; 5) El jefe, a su vez, tenía como obligación escuchar las propuestas de las "corporaciones" que se iban a establecer (artesanos, ganaderos, agricultores), aunque sus acciones eran absolutas y definitorias; 6) Todas las compras y ventas comerciales de la colonia debian hacerse por medio de una proveeduría, para no entrar en conflicto con los nativos; 7) La jefatura también se encargaría de que el régimen de propiedad pasara del comunal al privado y corporativo familiar, dejando un régimen comunal para "los pobres»; 8) los colonos se comprometían a defender la «integridad del hogar», de acuerdo con "la voluntad de Dios", y el que no cumpliera con este precepto sería expulsado; 9) Se expulsaría públicamente al individuo que maltratara a su esposa; 10) También se expulsaría a aquél que se embriagara, cometiera una falta o causara escándalo; 11) Se expulsaría al que vendiera o distribuyera bebidas embriagantes en cualquiera de sus formas; 12) Quedaría expulsado también todo aquél que robara; 13) el saludo para anunciarse sería "Ave María Purísima» Y la contestación: "Sin pecado concebida»; 14) Los padres tenían la obligación de inculcar a sus hijos el amor por la religión y la Iglesia católicas, en contraposición al «asesinato, al robo y al pecado mortal». Dentro de este precepto se prohibía portar armas en cualquiera de sus formas, así como los juegos de manos; 15) Las madres tenían por obligación enseñar a sus hijas a vestir con modestia. Se imponía el uso del vestido largo a todas las mujeres mayores de 14 años; 16) Todo mundo se obligaba a santiguarse antes y después de ingerir los alimentos; 17) Diariamente debía rezarse el rosario, ya fuera en las casas o en la iglesia; 18) A las 22 horas se imponía el toque de queda; 19) 
Se prohibían los bailes en cualquiera de sus formas, ya fuera en público o en privado; 20) La colonia se comprometía a enviar una delegación anual a la Basílica de Guadalupe, cada 12 de diciembre, así como una delegación a las juntas anuales de jefes del sinarquismo; 21) Los colonos se comprometían a respetar el lenguaje castellano, rechazando las "palabras pochas»; 22) El servicio médico se consideraba como un servicio público que tenía que controlar el jefe; 23) Establecido el régimen corporativo, la colonia debía mantener a las viudas y los huérfanos; 24) Cuando hubiera fiesta religiosa se permitía no trabajar, aunque el trabajo debía canalizarse a la construcción de utemplos, escuelas y carreteras" con la venia parroquial; 25) Se declaraba a la semana santa como de retiro espiritual, y se prohibían los viajes de placer o negocios; 26) La colonia se esforzaría en crear un patrimonio municipal a través de la producción del olivo; y 27) La educación se declaraba "católica y obligatoria» (25).

Las carencias de la colonia eran muchas y variadas. Abascal escribía casi a diario al Secretario de Colonización de la UNS, Juan Ignacio Padilla, solicitándole maquinaria, semillas para cultivos, materiales de construcción, ropa, alimentos y dinero en efectivo, al mismo tiempo que informaba de los diversos problemas de la colonia. La carencia de materiales para extraer el agua e irrigar los cultivos, se convirtió en una de las obsesiones cotidianas de Abascal, pues el comité nacional no mandaba lo indispensable para el sostenimiento de la obra colonizadora. Aunado a esto, los problemas internos de la colonia comenzaron a surgir, principalmente manifestados por la deserción de muchas familias. Sólo en los primeros meses partieron 25 de ellas, que no soportaron ni el ritmo de trabajo, ni el clima y las reglas autoritarias de Abascal. La falta de alimentación también cumplió su parte, y Abascal cada vez más subió el tono de sus cartas contra la falta de apoyo (26).

La situación de "María Auxiliadora» empezó a ser desesperada, según una carta de Abascal a Torres Bueno, fechada el 3 de mayo de 1942, donde afirmaba que la única fuente de ingresos era la que se enviaba de México, y las cosechas sólo se podrían

(25) ABASCAL. [1], págs. 463-465. Este proyecto se encuentra microfilmado en ACNUNS-BINAH, rollo 12.11.23, inserto también en el conjunto de correspondencia que tuvo la colonia con el Comité regional de la UNS en Guanajuato durante los primeros meses de 1942, ACRUNS-León.

(26) ABASCAL [1], págs. 469-499. La correspondencia era desesperadamente abundante entre 1942 y 1943 . Ésta se encuentra toda en ACRUNS-León, muestra diversos rollos de micropelicula en ACNUNS-BINAH. 
utilizar para subsistir (27). Poco a poco, la realidad demostraba que el proyecto de Abascal era una utopía irrealizable, pues lo que se necesitaba, principalmente, era el dinero suficiente para infinidad de necesidades. A pesar de todo, Abascal mencionaba en su correspondencia que la obra tendría éxito pasando un año, y que "María Auxiliadora" se convertiría en el bastión de los pueblos católicos, rescatados de las "garras revolucionarias".

Rafael Déveze, de la Brigada de Propaganda de la UNS, se convirtió en el principal ayudante de Abascal, pues era el enlace entre México, las autoridades del territorio y la colonia. Entre los dos se encargaban de conseguir los recursos necesarios para el funcionamiento de María Auxiliadora y, sobre todo, eran los que más presionaban al comité nacional para que enviara las peticiones y el dinero. Cada semana, el jefe de colonización de la UNS enviaba 500 pesos para la manutención de 350 personas; hacia septiembre de 1942, la suma ascendió a 650 pesos, suma que no subiría sino hasta mayo de 1943 (750 pesos). Era obvio que el dinero no alcanzaba para la manutención de las familias colonizadoras y mucho menos, para la compra de implementos para la agricultura, el bombeado del agua, la irrigación y otros proyectos que deseaba realizar el jefe (28).

Además, Abascal exigía el envío de profesores y sacerdotes, pues el funcionamiento de la cohesión dentro de la colonia era importante y, sobre todo, aseguraba el cumplimiento del proyecto de «pueblo ideal». El incumplimiento del comité nacional desesperaba continuamente al "cruzado", por lo que tuvo que recurrir al gobernador del territorio para lograr su apoyo en gastos altos (sobre todo de maquinaria). El gobernador Mújica ayudó en lo que pudo a Abascal, por lo que éste varió el concepto que tenía de aquel personaje (29).

La constante actividad de los colonos, ya sea en el trabajo, las asambleas o los actos simbólicos, los mantuvo a pesar de las necesidades y los conatos de deserciones que pulularon. Mientras tanto, Abascal empezó a sospechar de que había sido objeto de un juego sucio, y que las promesas de ayuda de Santacruz sólo

(27) La carta se encuentra en ACRUNS-León. Está reproducida por ABASCAL [1], págs. 513-520.

(28) Correspondencia de Abascal con Juan Ignacio Padilla, septiembre a diciembre de 1942, en ACRUNS-León. Ver también ABASCAL [1], págs. 550-570, MEYER [6] y DE LA VEGA, [9].

(29) Entrevista de Pablo Serrano Álvarez con el Dr. Rubén Mangas Alfaro, ya citada. Así se muestra también en diversos pasajes de las memorias de Abascal, también citadas. 
se habían dado para impulsarlo a aceptar su retirada de la jefatura nacional de la UNS. El líder comenzó a notar que la organización sinarquista tomaba diferentes virajes, sobre todo, a favor del gobierno y de los Estados Unidos, y que existía un decaimiento de la acción opositora del movimiento. Aunado a ésto, la falta de un apoyo global y efectivo para la colonia, le hizo pensar que los miembros de La Base y el jefe Torres Bueno habían intrigado para que la obra fracasara rotundamente, y él (Abascal) saliera desprestigiado ante el movimiento y la opinión pública. Hacia diciembre de 1942 se propuso viajar a México para aclarar los nubarrones que, definitivamente, habían sido reales y efectivos, por lo que $s u$ obra colonizadora, su utopía, estaba peligrando (30).

El mismo Abascal resumió la situación que experimentaba la colonia en 1943, ya cuando existía abiertamente el conflicto con Torres Bueno y los líderes de La Base:

Mi correspondencia, nutridísima, de enero a junio de 1943 es una pura repetición de los siguientes puntos: que padecemos hambre; que la desnutrición y la falta de partera y de médico eran fuentes innagotables de enfermedades costosas, al grado que había meses en que se juntaban en nuestra casa de La Paz de 30 a 40 personas, entre enfermos y familiares (...); que teníamos seis pulgadas de agua innagotable: cuatro en Santa Cruz [barrio de la colonia bautizado así por Abascal] y 2 en Don Vasco [nombre puesto también por Abascal a un barrio de la colonia] agua que no podíamos aprovechar bien, ya por falta de dinero para el combustible, ya por descompostura de los pésimos equipos de bombeo instalados (...); que teníamos otros dos pozos con mucha agua, sin motores para las bombas; y que la gente no podía producir más de lo que ya estábamos produciendo mientras no recibiéramos buena y suficiente maquinaria (31).

Para febrero de 1943 quedaba en la colonia una población de 282 personas, que fueron las que más resistieron las penurias, el duro trabajo, las enfermedades y el carácter del jefe Abascal. Mientras, los desertores y algunos miembros del comité nacional

(30) Abascal [1], págs. 593 y ss. Ver, además, José Trinidad Cervantes, ¿Qué han hecho los partidos politicos? La UNS, en letargo, está en espera de un lider, México, artículos publicados en "El Universal", UNS, s.f.; Joseph LEDIT, El frente de los pobres, México, Ediciones Spes, 1955; y las obras ya citadas de DE LA VEGA [9] y MEYER [6].

(31) Abascal. [1], págs. 593 y 594. 
hicieron una vasta propaganda contra el jefe de la colonia, tachándolo de "loco, desequilibrado y poseído por el demonio" (32).

Encolerizado, Abascal escribia al comité nacional quejándose de la ineficiencia y las restricciones económicas. Por medio de José Trueba, jefe de la colonia de Villa Kino, en Sonora, se había enterado que ésta recibía una buena cantidad semanal y que era favorecida con equipos necesarios y otros enseres (33). La fiscalización del trabajo de Abascal, por parte del nuevo secretario de Colonización, Felipe Navarro, y de Manuel Torres Bueno, que visitaron intempestivamente la colonia, enfrió aún más las relaciones, ocasionando el conflicto que empujó al fracaso de la obra colonizadora (34).

Mientras que entraba el proceso del fracaso, la colonia siguió sobreviviendo gracias a la venta del semanario El sinarquista (que religiosamente enviaba el comité nacional de la UNS), las constantes ayudas del gobernador Mújica y la venta de algunos productos cosechados por los colonos. La obra colonizadora de Baja California había costado a la UNS, hasta ese momento, 120.000 pesos, según consta en las partes de tesorería de la organización, hasta el mes de mayo de 1943 (35). Nada de lo prometido por Abascal, en su proyecto, se había cumplido por la carencia de los recursos, pero se había gastado mucho dinero.

La realización de la colonización favoreció el prestigio de la UNS como movimiento colaborador del gobierno avilacamachista $\mathrm{y}$, más aún, acrecentó el apoyo social de las masas que creyeron en el sinarquismo. Lo que fue irreversible, sin embargo, fue el conflicto que la obra colonizadora había ocasionado en el seno de la organización sinarquista y, sobre todo, en el marco de las relaciones entre los dirigentes. Un factor importante de esto fue la personalidad de Abascal que, obsesivo, se había lanzado a una empresa difícil, sin apoyos seguros y basado en planeamientos intuitivos y nada profesionales. Sobrevino pronto el final de la utopía.

(32) Entrevista de Pablo Serrano Álvarez con José Trinidad Cervantes, realizada en el Distrito Federal, los días 10, 11 y 15 de marzo de 1988. Cfr. con Salvador ABASCAL [1], págs. 600 y ss.

(33) Carta de Salvador Abascal a Juan Ignacio Padilla, marzo de 1943, ACRUNS-León.

(34) Abascal. [1], págs. 619 y ss.

(35) Ver esa documentación en ACNUNS-BINAH, rollo 12.78.66. 


\section{El FracASO}

A mediados de 1943, ante la falta de apoyo del comité nacional, el-cambio de orientaciones del movimiento y las intrigas entre los líderes, Abascal decidió romper con la UNS y con La Base, después de una discusión con Santacruz. El jefe de la colonia afirma que:

Con absoluta franqueza le dije que él [Santacruz] y Torres Bueno estaban llevando al sinarquismo por un despeñadero; que yo ya no era miembro de la organización: que si no lo hacía público era tan sólo por el bien de María Auxiliadora y por la esperanza - aunque leve, que aún me alentaba- de que pronto cayeran los dos tristes compadres, para que se dedicaran a la enseñanza del catecismo; que no entregaría yo la Jefatura de la Colonia sino en el momento arriba indicado [el apoyo completo a las necesidades de la colonia, y el cambio del entreguismo al gobierno]; y, por último, que si la Jefatura Nacional de la UNS seguía con su política de absoluta sumisión a poderes extraños y de sabotaje contra la Colonia, yo los atacaría públicamente a ellos dos, sin andarme por las ramas (36).

Abascal comprendió muy tarde que el proyecto de la colonización había sido apoyado, primero, para separarlo de la jefatura nacional de la UNS, y segundo, para que ante el fracaso saliera desprestigiado del movimiento y, sobre todo, ante los adversarios y la opinión pública. El líder tampoco visualizó la magnitud de la misma colonización, ni el conjunto de necesidades que requería para que tuviera éxito. La utopía era irrealizable desde el principio, pero la obsesión de Abascal por demostrar que el sinarquismo podía crear un orden lleno de "catolicismo", "felicidad" e "igualitarismo", se impuso (37).

El fracaso de la colonización bajacaliforniana era evidente, tanto en el nivel interno como en el externo: "Hay un hondísimo y tempestuoso descontento general por la falta de maquinaria y de alimentación suficiente. Nadie piensa ya en salir, sin embargo.

(36) Abascal [1], pág. 624. El subrayado es de Abascal. La correspondencia mantenida por Abascal y Déveze con el comité nacional evidenciaba el grado de enfrentamiento, en los sentidos que marca la cita. Esta documentación se encuentra en ACNUNS-BINAH en diversos rollos de microfilm, mientras otra parte está en ACRUNS-León. El conflicto que empujó al fracaso de la colonización sinarquista está expuesto por DE LA Vega [9], vol. 2 y por MEYer [6].

(37) Entrevista de Servando Ortoll y Pablo Serrano Álvarez con Gildardo Gonzálèz Sánchèz, citada en [15]. 
Es tiempo, pues, de salvar la obran, le escribía Abascal al Secretario de Colonización de la UNS, Gustavo Arizmendi (38). Los colonos, doscientos cincuenta en total, aguantaban la carencia de las más ínfimas necesidades, sólo los unía el «espíritu sinárquico-cristiano" que el jefe Abascal les había metido hasta la médula (39).

La situación era bastante crítica:

(...) en año y nueve meses no habíamos comido más carne que la de cinco reses entre todos. Gastábamos mucho en medicinas y tónicos para los anémicos y en alimentos especiales para los muy enfermos en La Paz. Castellanos [un médico] me decía que casi toda la Colonia estaba anémica y necesitadísima de una buena alimentación. La gente se quejaba de que ya no se sentía con fuerzas (40).

Los últimos meses de 1943, la colonia sobrevivió gracias a la ayuda del gobernador del territorio que, a petición de Abascal, dio maquinaria, semillas y alimentos. Mújica se convirtió en el benefactor de la colonia, lo que Abascal le agradeció. Aparte, se obtenían recursos de la venta del periódico sinarquista, así como de la venta de algunos productos cosechados por los colonos y que ofrecían en La Paz. La situación se tornó desesperada, y el jefe Abascal gestionaba por carta diversas ayudas, ya fuera con su familia política, miembros de la jerarquía eclesiástica o familias ricas que conocía en el centro del país (41).

El pleito con Torres Bueno se hizo abierto, por diferencias en cuanto al manejo de las orientaciones del movimiento, pero en el fondo el conflicto se debía a la falta de apoyo a la obra colonizadora de Abascal. En los primeros meses de 1944, los miembros de La Base y Torres Bueno, se movilizaron para encontrar una solución a las constantes críticas y amenazas de Abascal. Si éste descargaba su rencor contra ellos sería terrible, pues se daría a conocer que el sinarquismo estaba siendo dirigido por la Iglesia

(38) La carta puede consultarse en ACRUNS-León, aunque está reproducida de forma incompleta por ABASCAL [1], pág. 633. [32].

(39) Entrevista de Serrano Álvarez con José Trinidad Cervantes, ya citada

(40) ABASCAL [1], pág. 637. De esta situación no informaba El sinarquista, que siempre ensalzaba la obra colonizadora del sinarquismo.

(41) Alguna correspondencia de estas gestiones se encuentra en ACRUNSLeón. Esto se desprende también de Abascal [1], págs. 648 y ss. 
católica, y esto no convenía a los miembros de La Base por ningún motivo (42).

El 29 de marzo de 1944, la utopía sinarquista de la colonización bajacaliforniana se vendría abajo, pues Abascal fue separado hábilmente de la jefatura de la colonia. La llegada del padre Miguel Madrigal, supuestamente enviado del arzobispo de México Luis María Martínez, Manuel Zermeño, enviado de La Base y Torres Bueno, y José Valadés, a María Auxiliadora era para pedirle a Abascal que renunciara a la obra. En palabras del "cruzado" derrotado:

Padre - le dije con voz tranquila-, he pensado distinto: yo no he luchado, en realidad, sino por la Iglesia, pues la Patria sin la Iglesia no tiene para mí significado alguno. Es así que el Jefe de la Iglesia en México, su legítimo representante, me pide que entregue esto y mi honor; luego debo entregar una y otra cosa. La responsabilidad es suya. Al darle gusto a él no hago más que obedecer a mi Madre la Iglesia (43).

Dos días después, Abascal entregó la jefatura, bajo juramento ante la Iglesia y el arzobispo de México, de la colonia, José Valadés, y desde ese momento se convirtió en un adversario más del sinarquismo. Si había aceptado la separación como jefe de la obra colonizadora, era porque se le prometió que se daría apoyo suficiente para que siguiera existiendo y prosperara. En palabras de Abascal:

Dos razones más había para sacrificarme: la promesa, en la que el Padre [Madrigal] y yo creímos, de que si yo entregaba la Colonia recibiría ésta de inmediato toda la ayuda necesaria para su florecimiento. Y la segunda era que si yo no hubiera entregado, quizá se habría lanzado el entredicho, o sea, la excomunión, sobre el pueblo entero mientras yo no saliera de él (44).

Las deudas de la colonia eran muchas, pues se debía dinero al gobierno del territorio por la compra de una bomba para

(42) Ver, al respecto, Servando Ortoll, Las Legiones, La Base y el sinarquismo, ¿tres organizaciones distintas y un sólo fin verdadero? (1929-1948), mecanoescrito; del mismo autor, "Modes of historical Consciousness: Mexican sinarquistas and revolutionaries in the 1930s and 1940s a tentative appraisal", mecanoescrito, Columbia University; cfr. también con LEDIT [30] y MEYER [6].

(43) ABASCAL [1], pág. 680. Cfr. con Entrevista de James Wilkie y Wilkie con Salvador ABASCAL [2].

(44) ABascal [1], pág. 682. 
extraer agua, a varios colonos que habian prestado para diversas cosas y a sinarquistas de los Estados Unidos que habían prestado algún dinero al jefe Abascal. Los principales recursos de la colonia, en el momento en que este último dejó la jefatura, eran algunas joyas, 4 caballos, 16 mulas, 30 cerdos, 28 vacas, 28 becerros, 4 bueyes y 2 terneras, más lo construido para extraer el agua y los motores inservibles (45). La población de la colonia ascendía, en el momento de la partida de Abascal, a 247 personas que tuvieron que seguir soportando las penurias y enfrentar el conflicto entre los lideres y el cisma de la organización sinarquista. La obra colonizadora de Baja California costó, hasta el mes de marzo de 1944, la cantidad de 160.000 pesos, sin que hubiera tenido ningún éxito en relación al proyecto original (46).

La experiencia sinarquista de la colonización surcaliforniana había sido un rotundo fracaso. Con la partida del líder Abascal, que fue su creador, María Auxiliadora no tuvo más razónes de existir. El cisma interno de la UNS, a mediados de ese año, y el enfrentamiento con La Base y el gobierno, casi hacen desaparecer la presencia de los sinarquistas en México y causantes de los resultados de su obra colonizadora en Baja California. En poco menos de dos años, la colonia perdió el control de la Unión Nacional Sinarquista, aunque varios de los colonos aún siguen viviendo en esa zona. El proyecto y la utopía jamás se realizaron.

(45) Carta de José Valadés a Manuel Torres Buenos, 15 de abril de 1944, ACRUNS-León. Ver ABASCAL [1], pág. 684.

(46) Tesorería de la UNS, balance del primer trimestre de 1944, en ACNUNSBINAH, rollo 12.88 .123 . 